\title{
PSYCHOLOGICAL RECURRENCES AND INTERVENTION PROPOSAL FOR PATIENTS FOLLOWING BARIATRIC SURGERY
}

\author{
Aída M. Reséndiz Barragán, Mariana A. Sierra Murguía \\ "Dr. Manuel Gea González" General Hospital, Mexico City, Mexico \\ E-mail: aidaresendiz@hotmail.com,mariana.sierra.m@gmail.com
}

\begin{abstract}
Obesity has been declared by the World Health Organization (WHO) as an epidemic, due to a growth trend in obesity rates over the past 60 years and it is estimated that by 2015 there will be approximately 2.3 billion overweighed adults and 700 million obese adults worldwide. Bariatric surgery has shown to be the most effective intervention for the treatment of severe obesity with better long-term results. While most post-operative patients of bariatric surgery show improvement in psychopathology and quality of life, psychological recurrences have been identified thereafter. It has been reported that for people who have not been able to implement changes in their lifestyle, the result of the operation may not be optimal and may even be counterproductive with undesirable outcomes, such as recovery of lost weight, malnutrition, depression and anxiety, as well as using food as a soothing agent to stressful stimuli, present failures in following the diet, as well as dissatisfaction with the staff of the clinic

In recent years the number of bariatric surgeries performed annually has tripled showing a tendency to continue increasing, psychosocial and behavioral factors play a fundamental role in the long-term effects of the surgery; for this reason, the objective of this study is to describe the main psychological recurrences after bariatric surgery as well as a proposal for post-surgical cognitive behavioral group psychological support. Key words: bariatric surgery, obesity, post bariatric surgery, psychological intervention.
\end{abstract}

\section{Introduction}

Obesity has been declared by the World Health Organization (WHO) as an epidemic, due to a growth trend in obesity rates over the past 60 years and it is estimated that by 2015 there will be approximately 2.3 billion overweighed adults and 700 million obese adults worldwide (WHO, 2006).

Obesity is a risk factor for several diseases such as diabetes, hypertension, dyslipidemia, among others, for which it represents an important problem in public health matters worldwide, and a growing financial burden on national resources; for this reason, it is a primary task of the public health agencies to design and implement strategies for prevention and treatment.

The psychological consequences of severe obesity include: anxiety, depression and negative body image, discrimination, social isolation and stigmatization (Wadden \& Sarwer, 2006) and they can in turn contribute to the development of eating behavior disorders, body image dissatisfaction and depression; women are considered to be more vulnerable to these recurrences (Puhl et. al., 2007). 
Grade IV obesity, also called severe obesity, is significantly associated with an increased prevalence of comorbidities and with twice the prevalence of premature mortality compared to people with lesser degrees of obesity underlying the importance of prevention and treatment of this condition (Martins et al., 2010).

Bariatric surgery has shown to be the most effective intervention for the treatment of severe obesity with better long-term results (Sjostrom et al., 2004). Despite of the anatomic changes made by surgery, weight loss and long term maintenance are not guaranteed, the success of the procedure depends largely on behavioral changes made by patients and their ability to implement permanent changes in their lifestyle, such as adherence to diet and physical activity, as well as learning new ways of coping to avoid seeking for food in times of stress or distress (Bauchowitz et al., 2005).

Some reports show that not all patients benefit from surgery; there are significant differences in variations of weight in the short and long term after surgery (Kinzl et al., 2006); an example of this is that $20 \%$ of patients who undergo weight loss surgery, don't lose a significant amount of weight or recover it in the short term (Greenberg, Sogg \& Perna, 2009). The failure of this surgery in $20 \%$ of patients who do not achieve a significant weight loss is generally attributed to psychological or behavioral reasons (Busetto et al., 2005).

While most post-operative patients of bariatric surgery show improvement in psychopathology and quality of life, psychological recurrences have been identified thereafter. It has been reported that for people who have not been able to implement changes in their lifestyle, the result of the operation may not be optimal and may even be counterproductive with undesirable outcomes, such as recovery of lost weight, malnutrition, depression and anxiety, as well as using food as a soothing agent to stressful stimuli, present failures in following the diet, as well as dissatisfaction with the staff of the clinic (Bauchowitz et al., 2005; Bull et al., 1983; Orth et al., 2008).

Another line of research associated with patients who follow bariatric surgery is the eating behavior, identifying that many of them have disordered eating. After surgery a third part of the patients present binge eating episodes (Larsen et al., 2004) and vomiting after surgery (Kinzl et al., 2002) which adversely affect the results of the surgery. The presence of binge eating disorder has been associated with greater weight gain after surgery, especially between 2 and 7 years after surgery (Kalarchian et al., 2002) and vomiting conditions favor the development of eating behavior such as bulimia (Kinzl et al., 2002).

Some patients undergoing bariatric surgery experience body image dissatisfaction because of the aesthetic consequences of rapid weight loss, even after going through plastic surgery to reduce sagging (Kinzl et al., 2003). In turn, a higher incidence in social phobia and avoidant personality disorder has been reported in patients who don't agree to participate in counseling groups (Lier et al., 2011).

It is worth to highlight the importance of multidisciplinary work, especially the psychological aspect for which the treatment of obesity and the bariatric patient has been considered of great interest for psychology since severe obesity is associated with an increased prevalence of psychopathology, quality of life in patients with morbid obesity is greatly affected, their functionality is limited and, for patients to benefit from bariatric surgery and maintain these benefits, a change of lifestyle and good therapeutic adherence to the indications of a multidisciplinary team is necessary (Greenberg et al., 2004).

In recent years the number of bariatric surgeries performed annually has tripled showing a tendency to continue increasing (Buchwald, 2005), psychosocial and behavioral factors play a fundamental role in the long-term effects of the surgery (Van Hout, et al., 2006); for this reason, the objective of this study is to describe the main psychological recurrences after bariatric surgery as well as a proposal for post-surgical group psychological support.

\section{Characteristics of the Research}

We conducted a narrative literature research which primary objective was to identify the main psychiatric comorbilities presented after a bariatric surgery, in order to understand the psychiatric functioning of these patients. After the study we considered necessary to develop a 
program of psychological counseling for specific care of patients following bariatric surgery to provide them tools to handle such comorbilities.

\section{Follow- up Proposal}

In a meta-analysis in which the most popular psychological therapies for obesity treatment are reviewed, the results show that the most efficient and wide-spread used psychological approach for treating obesity is the behavioral-cognitive therapy, which being used as a part of a multidisciplinary treatment shows better results on weight loss and lifestyle changes; different kinds of psychotherapy are difficult to evaluate due to lack of methodology and the difficulty that represents to replicate the treatment (Shaw et. al., 2005).

Taking this information in consideration, we propose a scheme for follow-up that includes aspects to identify in patients following bariatric surgery (Table 1), the frequency of the interventions is every three months and a cognitive behavioral approach is recommended. If any of the aspects described is identified, individual psychological intervention is needed in order to aboard these issues specifically; the techniques suggested for this procedure are described as follows.

\section{Table 1. Psychological follow-up scheme for patients following bariatric surgery.}

\begin{tabular}{|c|c|c|}
\hline Time & Subject & Description of the stage \\
\hline $0-3$ months & $\begin{array}{l}\text { Adaptation } \\
\text { Therapeutic adherence } \\
\text { Anxiety } \\
\text { Psychosocial Functioning }\end{array}$ & $\begin{array}{l}\text { The patient must adapt to eat minor quantities compared to the } \\
\text { quantities he was used to consume and to experiment with different } \\
\text { kinds of food to discover gastric capacity and food tolerance. The } \\
\text { patient has to follow a strict food plan and has to take dietary } \\
\text { supplements. The patient might present "dumping"; must deal with } \\
\text { comments on their alimentation and appearance. }\end{array}$ \\
\hline 3-6 months & $\begin{array}{l}\text { Body Image } \\
\text { Anxiety } \\
\text { Psychosocial Functioning }\end{array}$ & $\begin{array}{l}\text { Rapid weight loss is more evident at this stage; the patient changes } \\
\text { the perception of his own body and gets comments and reactions of } \\
\text { the people with whom he lives. }\end{array}$ \\
\hline 6-12 months & $\begin{array}{l}\text { Body Image } \\
\text { Psychosocial Functioning } \\
\text { Depression } \\
\text { Anxiety } \\
\text { Eating Disturbances }\end{array}$ & $\begin{array}{l}\text { Weight loss can cause imbalances in the perception of the patient's } \\
\text { body image and psychosocial adjustment difficulties. } \\
\text { At this stage the patient's food tolerance is better and he knows } \\
\text { which types of food can cause him discomfort, so it is possible } \\
\text { to consume them in order to intentionally induce vomiting, in an } \\
\text { attempt to eat more. }\end{array}$ \\
\hline $\begin{array}{l}12 \text { months and more } \\
\text { (Every } 6 \text { months) }\end{array}$ & $\begin{array}{l}\text { Anxiety } \\
\text { Therapeutic Adherence } \\
\text { Body Image } \\
\text { Depression } \\
\text { Eating Disorders } \\
\text { Plastic Surgery }\end{array}$ & $\begin{array}{l}\text { Weight reaches a stabilization point and a proportion or the totality } \\
\text { of the lost weight may be regained. The patient may not be able } \\
\text { to make long-term changes so the improvements in psychological } \\
\text { functioning and eating habits presented at this point may be lost. } \\
\text { The patient may abandon medical consultation or present fear of } \\
\text { gaining weight. Skin flaps are observed due to rapid weight loss. } \\
\text { The patient has to face the actual result of the surgery, which may } \\
\text { not match his expectations. }\end{array}$ \\
\hline
\end{tabular}

Skills suggested for specific intervention:

The psychologist should select the techniques according to the patient's specific needs, some of the most used cognitive behavioral interventions for the psychological follow- up on obesity and bariatric surgery are described as follows.

Self- recording: It has been described that this technique is effective on promoting weight loss and weight maintenance. It has been used to promote the development of self-control and to monitor the target behavior (eating patterns, consumed calories, exercising, steps, heart beat per minute during exercise, sabotaging thoughts, etc.) in order to modify it so the desired results can maintain. Self-recording has proven to be an effective strategy on promoting weight control 
(Wing et al., 2006). Also, it allows to identify the basal frequency of a target behavior, it increases patient's attention towards that behavior and provides feedback about progress during the treatment (Butryn et al., 2007). It consists of making a daily register of the target behavior, it is important that these records could be made at the moment of occurrence or as close as possible. We suggest using this technique in all of the stages to promote adherence to meal and exercise plans, to medical indications and to identify automatic thoughts (in treatment of depression, anxiety and eating disorders).

Stimuli Control: Cognitive Behavioral treatment for obesity postulates that eating behavior is influenced by internal and external stimuli that are associated with the intake of certain food; Stimuli Control consists of identifying the stimuli that triggers food intake and modifying it in order to prevent a future episode of intake. The psychologist working with these patients should modify the stimuli that triggers overeating (less availability of junk food, avoid buffets, etc.) and sedentary behaviors (to limit "screen hours", the use of motor vehicles, etc.) and should promote physical activation (using altern transportation, subscribing to a gym, involving friends or family in exercising), and healthy eating (higher availability of fruits and vegetables, changing supermarket lists, etc.) (Van Dorsten, 2008). Family and social support are part of patient's environment, reason for involving them in lifestyle change. We suggest using this technique to promote therapeutic adherence.

Cognitive Therapy: The premise of cognitive therapy is that the interpretation or what a person thinks about themself or certain event has a direct impact on emotions and behavior. Patients with obesity sometimes present desadaptative cognitive schemes, dysfunctional beliefs related with body image, depressed mood, unrealistic weight goals, and food control. If these dysfunctional schemes get to be modified, healthy lifestyle can be promoted and weight regain prevented (Werrij et al., 2009). We suggest to implement this technique if the patient has depression, anxiety and eating disorders after the surgery.

Motivational Interview: It is a clinical interview centered on the patient, it helps to explore and resolve ambivalence about certain behavior or inappropriate habit in order to promote behavior change (Miller \& Rollnik, 2002), this could help patients make decisions about changing.

Problem Solving: When applied to obesity, this procedure teaches individuals to identify barriers for changing their lifestyle and to set possible solutions for them. It consists of five steps: 1 . Identifying the problem, 2. Proposing different solutions, 3. Analyzing benefits and disadvantages of each of the solutions proposed, 4. Carry on the solution chosen, 5. Evaluate if the solution was useful or not. This technique can be used also for involving social support, eliminating some types of food, planning social eating, etc.

Social Skills Training: This technique is focused on incrementing the skills of reacting in difficult situations (Goldsmith \& McFall, 1975); such are the changes and difficulties in personal relations caused by weight loss. In practice, social skills training consists of 4 stages: 1 . The development of a belief system that shows respect to other peoples thoughts as well as proper ones. 2. The development of the skills to carry on assertive behavior. 3. Cognitive Reestructuration focused on changing automatic thoughts in specific situations. 4. Behavior rehearsal in order to practice assertive responses. These stages can be developed in a no consecutive way and can be adapted and modified according to patient's needs (Lange, 1981).

Exposition: The focus on this technique should be the ability of the patient to expose to the feared situation or stimuli that has been negatively reinforced by avoidance (Marks, 1987). A brief and low intensity exposition produces slow and poor results, whereas a long and intense exposition produces fast and satisfactory results (Stern \& Marks, 1973), nevertheless, it is important to explain to the patient the nature of this treatment and to agree with him the objectives and stages of this exposition, coming up to an agreement respecting to each session's intensity. By using this method, the patient is supposed to realize that the real barrier is the fear itself and not any physical characteristic (Newell \& Dryden, 1991), reason why it is useful to decrement body image issues.

Relaxation Techniques: Stress inoculation, used to improve the way in which patients copy different situations, is divided in three stages: cognitive preparation, skill acquisition and apply- 
ing what learned. During the training, the patient is induced to relaxation exercises, cognitive restructuring, guided imaginery, modeling and roleplaying with the objective of providing him with

skills to help him copy more efficiently with problematic situations (Meichenbaum, 1975).

Psychoeducation: The difference between psychoeducation and traditional educative interventions is that the first, focuses on improving patient's life whereas the second focuses only on providing information. According to diverse authors, psychoeducation should be an essential part of the integral treatment of chronic diseases (Wagner, Austin \& Von Korff, 1996) and the information provided to the patients should be part of dialy practice in order to promote independence and quality of life of those who suffer a chronic disease like obesity (Rankin \& Stallings, 2001).

\section{Conclusions}

Obesity has been considered a world epidemic because of the fast increment of growing rates. Bariatric surgery is the gold standard for people with severe obesity because of the effects on weight loss and the improvement of comorbidities. It has also been observed that psychological functioning can improve after bariatric surgery, whereas, there are psychological comorbidities that can affect the outcome of the surgery as well as individual's functionality and short and long term quality of life. The present paper presented a suggestion of group cognitive behavioral therapy for post bariatric surgical patients, which included the most common psychological comorbidities referred on research, as well as techniques suggested for their treatment. The need to offer a psychological follow up for these patients after their surgery is convincing by knowing that it is a non-reversible procedure that demands considerable lifestyle modification. Nevertheless, there are not much follow up programs available for these patients that offer structured guidelines, reason for which the importance of designing these interventions is pointed out in order to benefit the patients and the multidisciplinary team that works with them.

\section{References}

Bauchowitz, A., Gonder-Frederick, L., Olbrisch, M., Azarbad, L., Ryee, M., Woodson, M., Miller, A., \& Schirmer, B. (2005). Psychosocial evaluation of bariatric surgery candidates: A survey of present practices. Psychosomatic Medicine, 67 (5), 825-832.

Buchwald, H. (2005). Bariatric Surgery for morbid obesity: Health implications for patients, health professionals, and third party payers. Journal of American College of Surgeons, 200 (4), 593-604.

Bull, R., Engels, W., Engelsmann, F. \& Bloom, L. (1983). Behavioral changes following gastric surgery for morbid obesity: A prospective, controlled study. Journey of Psychosomatic Response, 27 (6), 457-467.

Busetto, L., Segato, G., De Luca, M., De Marchi, F., Vianello, M., Valeri, M., Favretti, F. \& Enzi, G. (2005). Weight loss and postoperative complications in morbidly obese patients with binge eating disorder treated by laparoscopic adjustable gastric banding. Obesity Surgery, 15 (2), 195-201.

Butryn, M. L., Phelan, S., Hill, J. O. \& Wing, R. R. (2007). Consistent self-monitoring of weight: A key component of successful weight loss maintenance. Obesity, 15 (12), 3091-3096.

Goldsmith, J. \& McFall, R. (1975). Development and evaluation of an interpersonal skill-training program for psychiatric inpatients. Journal of Abnormal Psychology, 84 (1), 51-58.

Greenberg, I., Smith, K., \& Rockart, E. (2004). Behavioral Health evaluations in Bariatric Surgery. Nutrition in Clinical Care, 7 (1), 5-11.

Greenberg, I., Sogg, S., \& Perna, F. (2009). Behavioral and psychological care in weight loss surgery: Best practice update. Obesity, 17 (5), 880-884.

Kalarchian, M., Marcus, M., Wilson, G., Labouvie, E., Brolin, R. \& LaMarca, L. (2002). Binge eating among gastric bypass patients at long-term follow-up. Obesity Surgery, 12 (2), 270-275.

Kinzl, J., Trefalt, E., Fiala, M. \& Biebl, W. (2002). Psychotherapeutic Treatment of Morbidly Obese Patients after Gastric Banding. Obesity Surgery, 12 (2), 292-294. 
Kinzl, J., Traweger, C., Trefalt, E. \& Biebl, W. (2003). Psychosocial consequences of weight loss following gastric banding for morbid obesity. Obesity Surgery, 13 (1), 105-110.

Kinzl, J. F., Schrattenecker, M., Traweger, C., Mattesich, M., Fiala, M. \& Biebl, W. (2006). Psychosocial predictors of weight loss after bariatric surgery. Obesity Surgery, 16 (12), 1609-1614.

Lange, A. (1981). Etnisk Deskriminering och Social Identitet: Forskninngsoversikt och Teoretsk Analys. Stockholm: Liber Forlag.

Larsen, F., Van Ramshorst, B., Geenen, R., Brand, N., Stroebe, W. \& Van Doornen, L. (2004). Binge eating and its relationship to outcome after laparoscopic adjustable gastric banding. Obesity Surgery, 14 (8), 1111-1117.

Lier, H., Biringer, E., Stubhaug, B., Eriksen, H. \& Tangen, T. (2011). Psychiatric Disorders and Participation in Pre- and Postoperative Counselling Groups in Bariatric Surgery Patients. Obesity Surgery, 21 (6), $730-737$.

Marks, I. (1987). Fears, Phobias and Rituals: Panic, Anxiety, and Their Disorders: Panic, Anxiety, and Their Disorders. New York: Oxford University Press.

Martins, C., Strommen, M., Stavne, O., Nossum, R., Marvik, R., \& Kulseng, B. (2010). Bariatric Surgery versus Lifestyle Interventions for Morbid Obesity - Changes in Body Weight, Risk Factors and Comorbidities at 1 Year. Obesity Surgery, published online 09 April 2010. Retrieved on February 2013 from http://www.motivationcenters.com/documents/fichiers/BARIATRIC_SURGERY_VS_ LIFESTYLE_CHANGE.PDF

Meichenbaum, D. (1975). Stress inoculation training. New York: Pergamon Press.

Miller, W., \& Rollnick, S. (2002). Motivational interviewing: Preparing people for change. New York: Guilford Press.

Newell, R. \& Dryden W. (1991). Clinical problems an introduction to the cognitive-behavioural approach. In: Dryden, W. \& Rentoul, R. (Eds)., Adult Clinical Problems: A Cognitive-Behavioural Approach (pp. 27-55). London: Routledge.

Orth, W., Madan, A., Taddeucci, R., Coday, M., \& Tichansky, D. (2008). Support group meeting attendance is associated with better weight loss. Obesity Surgery, 18 (4), 391-394.

Puhl, R. M., Moss-Racusin, C. A., \& Schwartz, M. B. (2007). Internalization of weight bias: Implications for binge eating and emotional well-being. Obesity, 15 (1), 19-23.

Rankin, S., \& Stallings, K. (2001). Patient education: Principles \& practice. Philadelphia: Lippincott.

Shaw, K., O'Rourke, P., Del Mar, C. \& Kenardy, J. (2005). Psychological interventions for overweight and or obesity (Review). Cochrane Database of Systematic Reviews, 2, Art. No.: CD003818.

Sjöstrom, L., Lindroos, A.K., Peltonen, M., Torgerson, J., Bouchard, C., Carlsson, B., Dahlgren, S., Larsson, B., Narbro, K., Sjöstrom, C.D., Sullivan, M., \& Wedel, H. (2004). Lifestyle, diabetes, and cardiovascular risk factors 10 years after bariatric surgery. New England Journal of Medicine, 351 (26), 2683-2693.

Stern, R. \& Marks, I., (1973). Brief and prolonged flooding, a comparison in agoraphobic patients. Archives of General Psychiatry, 28 (2), 270-276.

Van Dorsten, B. \& Lindley, E. (2008). Cognitive and Behavioral Approaches in the Treatment of Obesity. Endocrinology and Metabolism Clinics of North America, 37, 905-922.

Van Hout, G., Boekestein, P., Fortuin, F., Pelle, A., Van Heck, G. (2006). Psychosocial Functioning following Bariatric Surgery. Obesity Surgery, 16, 787-794.

Wadden, T., \& Sarwer, D. (2006). Behavioral assessment of candidates for bariatric surgery: A Patient oriented approach. Obesity, 14 Suppl 2, 53S-62S.

Wagner, E., Austin, B., \& Von Korff, M. (1996). Organizing Care for Patients with Chronic Illness. The Milbank Quarterly, 74 (4), 511-544.

Werrij, M., Jansen, A., Mulkens, S., Elgersma, H., Ament, A., \& Hospers, H. (2009). Adding Cognitive Therapy to dietetic treatment is associated with less relapse in obesity. Journal of Psychosomatic Research, 67 (4), 315-324. 
WHO (2006). Obesidad y sobrepeso ¿Qué son la obesidad y el sobrepeso?, Nota Descriptiva $\mathrm{N}^{\mathrm{o}} 311$, Volume 5, 2013 recuperado el 19 de noviembre del 2009 de http://www.who.int/mediacentre/factsheets/fs311/es/ index.html

Wing, R., Tate, D., Gorin, A., Reynor, H., \& Fava, J. (2006). A self-regulation program for maintenance of weight loss. New England Journal of Medicine, 355, 1563-1571.

Advised by Stanislava Yordanova Stoyanova, South-West University "Neofit Rilski”, Bulgaria

Received: January 31, 2013

Accepted: February 17, 2013

Aída M. Reséndiz Barragán Bachelor in Psychology, Researcher, "Dr. Manuel Gea González" General Hospital, Calzada de Tlalpan 4800, Col. Sección XVI, CP14080

Mexico City, Mexico.

E-mail: aidaresendiz@hotmail.com

Mariana A. Sierra Murguía

Master in Psychology, Researcher, "Dr. Manuel Gea González" General Hospital, Calzada de Tlalpan 4800, Col. Sección XVI, CP14080 Mexico City, Mexico.

E-mail: mariana.sierra.m@gmail.com 